\title{
واقع استخدام المعلمين للتقنيات التعليمية من وجهة \\ نظر مديري المدارس
}

\section{أ.تحمد رمضان شعيب}

كلية الآداب/جامعة مصراتة

\section{مقدمة:}

يعد المعلم ركيزة أساسية من ركائز العملية التربوية، بل هو عصب العملية التربوية

وحجر الزاوية فيها ومحورها الأساسي، والعنصر الفاعل في أية عملية تربوية، وإن أي إصلاح أو أو تطوير أو تجديد في العملية التربوية يجب أن يبدأ بالمعلم؛ إذ لا تربية جيدة بدون معلم جيد، غير أن المعلم في عصر المعلومات لم يعد يشكل المصدر الوحيد للمعرفة؛ إذ تعددت مصادر المعرفة وطرق الحصول عليها، وأصبح دور المعلم وسيطاً ومسهالًا بين التلاميذ ومصادر المعرفة، وأصبح

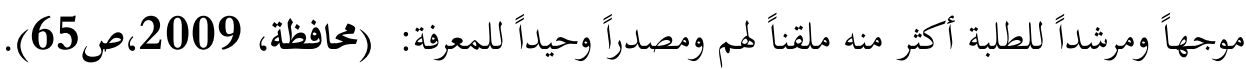
وعلى العموم تتفق آراء المربين وصانعي القرارات التربوية مع نتائج البحوث التربوية الحديثة على أن نجاح المؤسسة التربوية في عصر تكنولوجيا المعلومات والاتصالات - الذي يتسم بتضخم المعرفة وتنوع مصادرها وطرق اكتساها ووسائط تعلمها - يتوقف بالدرجة الأولى على بحاحها في إحداث نقلة نوعية في إعداد المعلم وإعادة تأهيله كي يتعامل مع تكنولوجيا

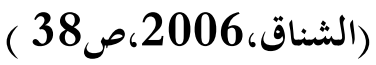
المعلومات دون رهبة أو خوف أو توجس. ويشهد العالم في مطلع القرن الحادي والعشرين تطوراً مذهلاً في كافة مناحي الحياة؛ وخاصة في بحال تكنولوجيا المعلومات والاتصالات؛ مما يستدعي أن تواكب المؤسسات التربوية هذا التطور وذلك بإعداد المعلمين وتأهيلهم مهنياً وتربوياً وعلمياً ومسلكياً؛ باعتبارهم عصب العملية التربوية وأداة بجاحها، وأن نوعية التعليم ومدى تحقيق الأهداف التربوية والارتقاء بمستوى أداء

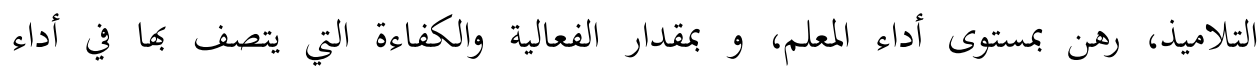
رسالته؛ الأمر الذي جعل الدول على اختلاف فلسفاتا وأهدافها تولي الارتقاء بمستوى أداء 
المعلم جُحلَّ اهتمامها وعنايتها. وبحمل القول: فإن المعلم مطلوب منه القيام بأدوار متعددة، كإدارة الصف، وعرض المتتوى التعليمي لمادته بصورة جيدة، والبحث عن المعرفة، وتشخيص

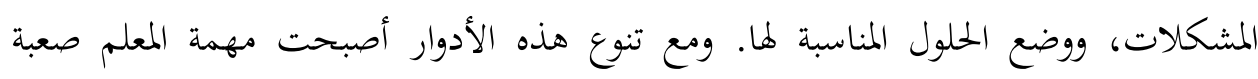

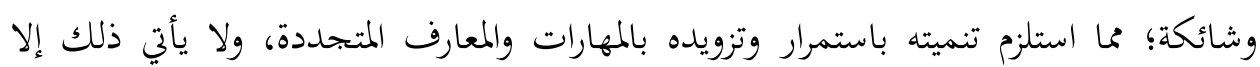

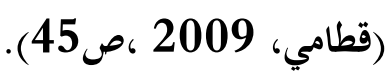
بالإعداد الجيد المستدام مأمسام مشكلة البحث:

إن تحديات المستقبل لا بد وأن تؤثر على دور المعلم ومهماته التي لا بد وأن يعيها المعلم؛ حتى يتمكن من أداء رسالته على أكمل وجحه، وأهم تحديات المستقبل : الانفجار

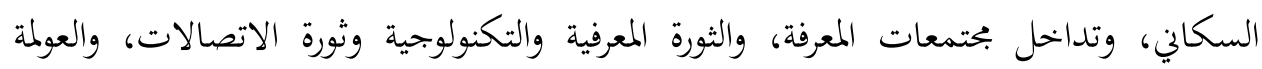
الاقتصادية والثقافية والسياسية والتربوية، وكذلك هيمنة القطب الواحد على ميادين العلوم والابتكارات، إلى جانب الفقر والتخلف الذي يرمي بتلابيبه على دول العالم الثالث ومعظم أقطار العالم العربي منه ، وتتحد مشكلة البحث بالإجابة عن السؤال الرئيس :

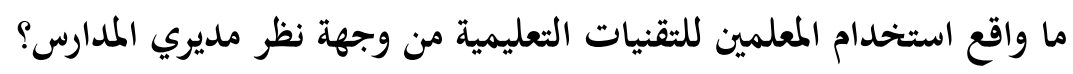

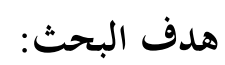

التعرف على واقع استخدام المعلمين للتقنيات التعليمية من وجهة نظر مديري المدارس .

$$
\text { أهمية البحث : }
$$

1- قد يكون هذا البحث إضافة للمكتبة التربوية .

2- قد يسهم البحث في إبراز الدور الذي تلعبه التقنيات التربوية في العملية التربوية.

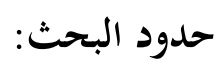

تتحدد نتائج هذا البحث في ضوء كل من الحدود التالية: 1. الحدود البشرية: يقتصر البحث الحالي على عينة عشوائية من مديري المدارس في في مدينة مصراتة. 2. الحدود المكانية: يقتصر البحث الحالي على مديري المدارس في مدينة مصراتة. 
3. الحدود الزمانية: طبق هذا البحث خلال الفصل الدراسي الثاني من العام الدراسي

$$
\text { .(2015) }
$$

\section{ثانياً : الدراسات السابقة}

أجرى ملكاوي و بنحادات (2007) دراسة استهدفت التعرف على أهم التحديات والقضايا التي تواجه التربية العربية خلال القرن الحالي،كالتحدي الثقافي، والتربية المستدامة، وقيادة التغيير، وثورة المعلومات، وتمهين التعليم، والأزمة البيئية، لتكون منطلقاً في إبراز

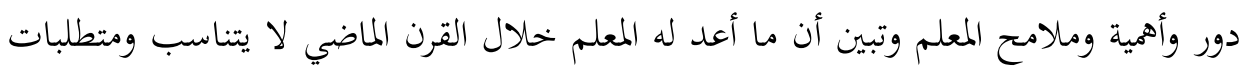
الدور الذي سيؤديه خلال القرن الحالي؛ حيث مدارس المستقبل الإلكترونية، والتعليم الإلكتروني

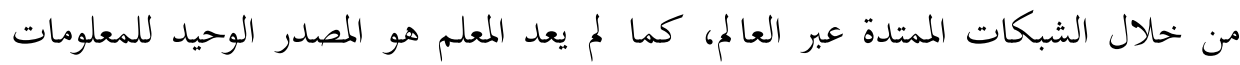
والمعارف؛ فهناك وسائل ومصادر متنوعة ومتعددة تضخ كميات هائلة من المعلومات، يستطيع الطلبة بسهولة ويسر تلقيها؛ فتؤثر فيهم؛ مما يفرض على للمعلم تنمية قدراته الفكرية والثقافية

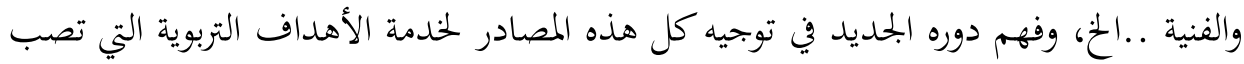
في مصلحة وطنه وأمته، وأن يدرك أن المعرفة والتحكم بها هي أهم مصادر الثروة، وأن الترابطية لا الانفصالية، والتكامل وليس التجزؤ، وفورية الوقت الفعلي لسرعة المراحل المتسلسلة هي التي تشكل أساس النموذج التربوي الجديد.

واستخلصت الدراسة بعض الملامح والأدوار للمعلم ليستطيع أداء رسالته بحيث يكون

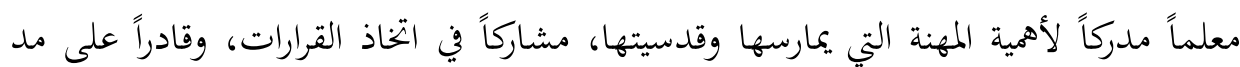
العملية التعليمية خارج أسوار المدرسة، مدركاً لموقعه وأهميته في عصر العولمة والتقدم والانفتاح، خبيراً في طرق البحث عن المعلومة، يستند في عمله وسلوكه وممارساته إلى قاعدة

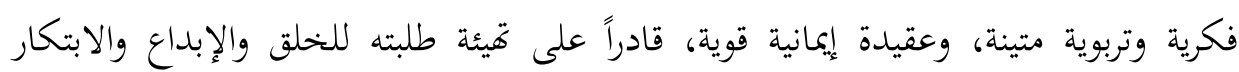

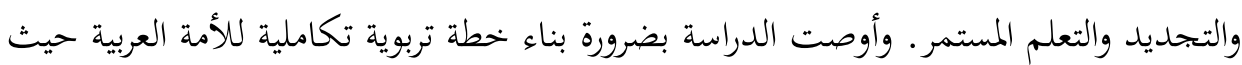
الظروف متشاهة، مستندين بتخطيطهم على البحث الميداني للواقع الحقيقي للمعلم والعملية 
أما دراسة عبابنة وشعيب هدفت (2009) إلى التعرف على أثر تكنولوجيا المعلومات والاتصالات على النظام التربوي، استخدم الباحثان المنهج التحليلي للوصول إلى هدف الدراسة، وكان من نتائجها فيما يتعلق بالمعلم: • سيتغير دوره فيصبح المرشد والميسر لتعلم الطلبة، ولم يعد المسيطر ومركز العملية التربوية

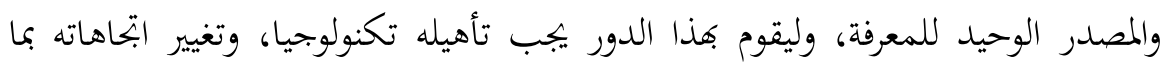
يتناسب ودوره الجديد، وأن يمتلك محموعة من الكفايات والمهارات الجديدة. هيتلب منه (أي المعلم) امتلاك بحموعة من الكفايات والمهارات الجمديدة، وهي: تمكنه من استخدام أدوات (ت م ص)، وحرصه على إبراز دور الطالب الموري في العملية التربوية، والارتقاء به، والمقدرة الواعية على توظيف المواد التعليمية المحوسبة بالشكل الذي دوري

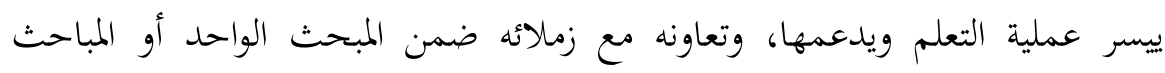

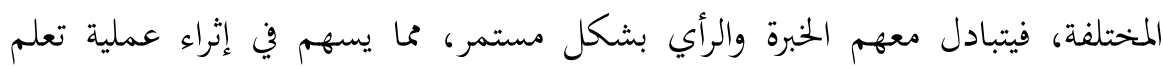
الطلبة، وسعيه للوصول إلى مصادر تعليمية جديدة، واهتمامه بالنمو المعرفي والتطور المهني له ولطلابه، وامتلاكه مهارات حديثة في استراتيجيات التقويم، وعلاقاته مع الطلبة وزملائه المعلمين: وتحتاج هذه العملية إلى اتصال أفقي بين المعلم وزميله كما تقوم على تبادل

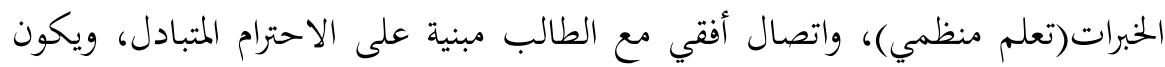

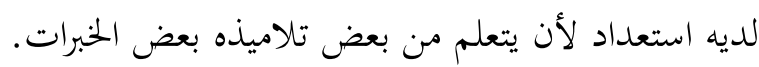
تعقيب على الدراسات السابقة: • يغلب عليها المنهج التحليلي. • هدفت إلى التنبؤ بأدوار وخصائص المعلم في ضوء ثورات تكنولوجيا المعلومات والاتصالات. منهج البحث: لتحقيق أهداف البحث اتبع الباحث المنهج الوصفي المسحي. 


$$
\text { مجتمع البحث: }
$$

تكون بحتمع الدراسة من جميع مديري المدارس في مدينة مصراتة الذي بلغ عددهم(100)

مدير .

عينة البحث :تم اختيار عينة الدراسة من بحتمع الدراسة بلغت (25) مديرًا بمدينة مصراتة

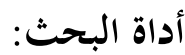

تم بناء استبانة الدراسة وذلك بالرجوع إلى الأدب النظري المتعلقة بالتقنيات التعليمية؛ حيث

$$
\text { تكونت صياغتها الأولية من (45 فقرة)،وأربعة بحالات . }
$$

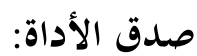

للتأكد من صدق الأداة تم عرضها على بحموعة من المحكمين المتخصصين في قسم

$$
\text { التربية، تم تعديل (14) فقرة . }
$$

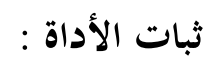

للتأكد من ثبات الأداة فقد تم تطبيقها على عينة بلغت (10) من مدراء المدارس ،وبعد

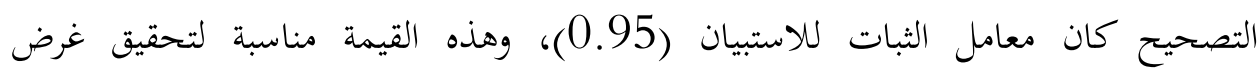
البحث، وبذلك تكونت الأداة بصورةقا النهائية من (45)فقرة. نتائج البحث:

\section{ما واقع استخدام المعلمين للتقنيات التعليمية من وجهة نظر مديري المدارس ؟} للإجابة عن هذا السؤال تم حساب المتوسطات الحسابية والانحرافات المعيارية ودرجة الموافقة لجميع فقرات حسب المجالات موزعة وفق الجداول وهى كما يلي . 


$$
\text { جدول (1) }
$$

المتوسطات الحسابية والانحرافات المعيارية ودرجة الموافقة لجميع فقرات مجال أدوار

المعلم مرتبة تنازليا

\begin{tabular}{|c|c|c|c|c|c|}
\hline درجة & الانمرف & المتوسط الحسابي & 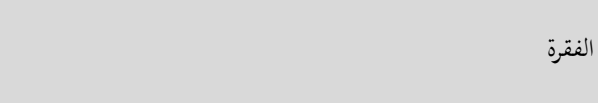 & رقم الفقرة & 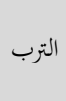 \\
\hline كبيرة & 0.80 & 4.28 & يوظف التقنيات التعليمية في حل المشكلات التعليمية. & 8 & 1 \\
\hline كبيرة & 0.86 & 4.25 & يساعد الطلاب في الوصول إلى المعلومات. & 4 & 2 \\
\hline 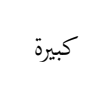 & 0.76 & 4.18 & يسهل تعلم الطلاب عندما يواجهون صعوبة ترتبط التقنيات & 2 & 3 \\
\hline كبيرة & 0.83 & 4.13 & يرشد الطلاب أثناء التعلم في اختيار مصادر المعرفة المناسبة. & 5 & 4 \\
\hline 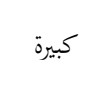 & 0.97 & 4.13 & يرشــد الطـلاب إلى طــرق الوصـول إلي المعرفة باستخدام التقنيات & 1 & 5 \\
\hline 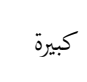 & 0.74 & 4.01 & يوفر الأمن الجسمي والنفسي للطلبة أثناء استخدام التقنيات & 7 & 6 \\
\hline 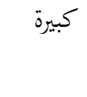 & 0.99 & 3.99 & يشارك الطلاب في اكتساب المعرفة وتوظيفها . . & 9 & 7 \\
\hline كبيرة & 0.90 & 3.92 & يقود عملية تعلم الطلاب من خلال التقنيات التعليمية. & 3 & 8 \\
\hline 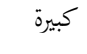 & 1.05 & 3.92 & يحاور ويناقش الطلاب باستخدام التقنيات التعليمية . & 6 & 9 \\
\hline كبيرة & 0.88 & 4.1 & \multicolumn{3}{|c|}{ ابمال الكلي } \\
\hline
\end{tabular}




\begin{tabular}{|c|c|c|c|c|c|}
\hline درجة الموافقة & المعياري الاكراق & المتوسط الحسابي & الفقرة & 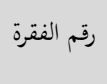 & 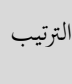 \\
\hline جدا كبيرة & 0.84 & 4.28 & يواكب علوم العصر وتقنياته. & 21 & 1 \\
\hline كبيرة & 0.84 & 4.17 & الإلكتروين. & 20 & 2 \\
\hline 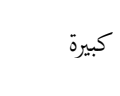 & 0.83 & 4.14 & المتوفيز بين الإنترنت المعارف المناسبة والمعارف غير المناسبة & 16 & 4 \\
\hline كبيرة & 0.82 & 4.14 & يوظف الإنترنت في الحصول على المعرفة . & 11 & 3 \\
\hline كبيرة & 0.65 & 4.13 & يختار الأنشطة الإلكترونية المناسبة لأهداف الدرس. & 19 & 5 \\
\hline كبيرة & 0.92 & 4.07 & يقيم تصصيل الطلبة بناء على أدائهم أثناء استخدام & 17 & 6 \\
\hline كبيرة & 0.80 & 4.04 & يستخدم الحاسوب للتخطيط للحصة الصفية. & 10 & 7 \\
\hline كبيرة & 1.12 & 3.10 & يمتلك المقدرة على اختيار مصادر المعرفة المناسبة. & 13 & 8 \\
\hline كبيرة & 0.81 & 3.10 & يدرس باستخدام المناهج الموسبة. & 18 & 9 \\
\hline 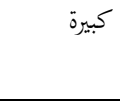 & 1.09 & 3.94 & الإنحليزية. المفاهيم الأساسية في تخصصه باللغة & 14 & 10 \\
\hline كبيرة & 0.91 & 3.80 & يعد مواد تعليمية داعمة للمنهج بالحاسوب. & 15 & 11 \\
\hline 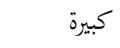 & 0.19 & 3.64 & يعتلك الرخصة الدولية لقيادة الحاسوب. & 12 & 12 \\
\hline كبيرة & 0.82 & 3.9 & & & الجمال ال - ال \\
\hline
\end{tabular}

\section{نلاحظ من الجدول رقم (1) : (1)}

كان متوسط درجة الموافقة على أدوار المعلم (4.1) وتقابل درجة موافقة كبيرة.

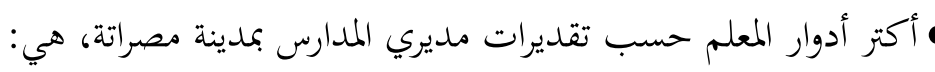
الفقرة (8) "يوظف التقنيات التربوية في حل المشكلات التعليمية" بمتوسط حسابي (4.28)، ثم

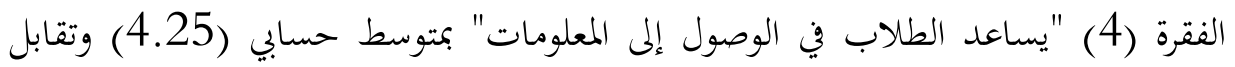
درجة موافقة كبيرة جدا. * بينما جاءت الفقرتان (3 ، 6) في المرتبة الأخيرة لفقرات هذا ابلحال، كأقل الأدوار بمتوسط حسابي (3.92) لكل منها. 


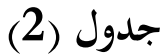

\section{المتوسطات الحسابية والانحرافات المعيارية ودرجة الموافقة لجميع فقرات مجال معارف}

\begin{tabular}{|c|c|c|c|c|c|}
\hline المورافقة & الانحراف المعياري & المسابي - المتوسط & 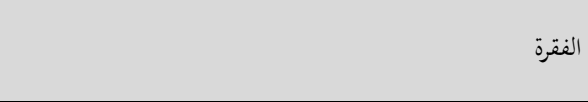 & 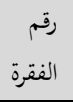 & 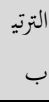 \\
\hline كبيرة & 0.80 & 4.28 & يمتلك مهارات تنظيم المعرفة وتحليلها واختيار الملائم منها. & 24 & 1 \\
\hline كبيرة & 0.75 & 4.17 & يمتلك المقدرة على الدخول على قواعد البيانات. & 32 & 2 \\
\hline كبيرة & 0.72 & 4.14 & يمتلك المقدرة على استخدام وسائل التعلم عن بعد . & 22 & 3 \\
\hline كبيرة & 0.75 & 4.14 & يستخدم الوسائط المتعددة في التعليم والتعلم & 31 & 4 \\
\hline كبيرة & 0.98 & 4.13 & ينمي مهارات التفكير المنظم باستخدام (تمص). & 33 & 4 \\
\hline كبيرة & 0.85 & 4.07 & يتقن استخدام برامج الكلمات (الوورد) . & 25 & 6 \\
\hline كبيرة & 0.86 & 4.04 & يتقن استخدام برامج العرض التقديمية (بوربوينت). & 29 & 6 \\
\hline كبيرة & 0.91 & 3.10 & يستخدم السبورة الذكية التعليم وللتعلم. & 30 & 8 \\
\hline كبيرة & 0.90 & 3.10 & يمتلك مهارات البحث باستخدام محركات البحث مثل جوجل. & 34 & 8 \\
\hline كبيرة & 0.86 & 3.94 & عبر الأشرطة. & 23 & 10 \\
\hline كبيرة & 0.87 & 3.94 & يؤمن بأنه ليس المصدر الوحيد للمعرفة. & 26 & 11 \\
\hline كبيرة & 0.97 & 3.83 & يتقن استخدام برنامج الأكسل. & 27 & 12 \\
\hline كبيرة & 0.88 & 3.76 & يتقن استخدام برنامج الرسام . & 28 & 13 \\
\hline كبيرة & 0.79 & 4.06 & \multicolumn{3}{|c|}{ البحال الكلى } \\
\hline
\end{tabular}

\section{معلم مرتبة تنازلياً}

\section{نلاحظ من الجدول رقم (2) :}

كان متوسط درجة الموافقة على معارف المعلم (3.9) وتقابل درجة موافقة كبيرة. أكثر معارف المعلم حسب تقديرات مدراء المدارس بمدينة مصراتة، هي: الفقرة (21) "يواكب علوم العصر وتقنياته المتطورة" بمتوسط حسابي (4.48)، وتقابل درجة موافقة كبيرة جداً. تم الفقرة (20) "يمتلك المقدرة على إدارة الصفوف الافتراضية والتعلم الإلكتروني" بمتوسط حسابي (4.17) وتقابل درجة موافقة كبيرة. 
* بينما كانت الفقرتان (15) و(12) أقل المعارف التي وافق عليها مدراء المدارس لمعلم ، بمتوسط حسابي (3.80) و3.64) على الترتيب.

$$
\text { جدول (3) }
$$

المتوسطات الحسابية والانخرافات المعيارية ودرجة الموافقة لجميع الفقرات في مجال

\section{مهارات المعلم مرتبة تنازليا}

$$
\text { نلاحظ من الجدول رقم (3) : }
$$

كان متوسط درجة الموافقة على معارف المعلم (4.06) وتقابل درجة موافقة كبيرة.

$$
\text { • أكثر مهارات المعلم حسب تقديرات مديري المدارس بمدينة مصراتة، هي: }
$$

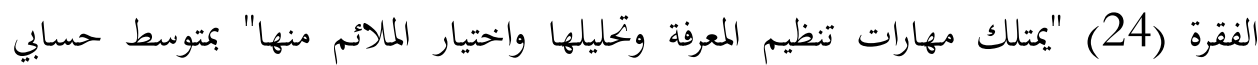

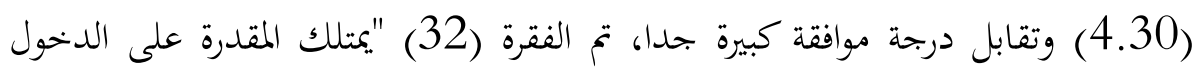
على قواعد البيانات" بمتوسط حسابي (4.21) وتقابل درجة موافقة كبيرة جدا. * بينما كانت الفقرتان (27 و28) كأقل مهارات للمعلم بمتوسط حسابي (3.76) و(3.83) على الترتيب. 
(4) (4) (1)

المتوسطات الحسابية والانحرافات المعيارية ودرجة الموافقة لجميع فقرات بجال قيم المعلم

مرتبة تنازلياً

\begin{tabular}{|c|c|c|c|c|c|}
\hline الموافقة & المعياري & المستوسط & 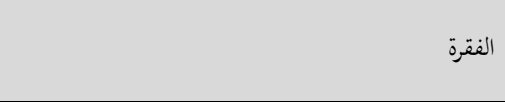 & رقفم & 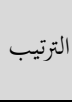 \\
\hline كبيرة & 0.69 & 4.55 & يدرك أهمية المهنة التي يمارسها وقدسية رسالتها . & 45 & 1 \\
\hline كبيرة & 0.64 & 4.24 & يعتقد بضرورة تدربه على الجحديد في التقنيات التعليمية. & 42 & 2 \\
\hline كبيرة & 0.81 & 4.23 & ينمي نزعة التعلم الذاتي له ولطلابه. & 35 & 3 \\
\hline كبيرة & 0.87 & 4.23 & يلتزم بحقوق الملكية الفكرية. & 43 & 3 \\
\hline كبيرة & 0.72 & 4.18 & يعتقد أن التقنيات التعليمية تزيد من أهمية دوره كمعلم . & 36 & 5 \\
\hline كبيرة & 0.97 & 4.17 & يؤمن بأنه لا يمتلك الإجابات الصحيحة لكل الأسئلة . & 39 & 6 \\
\hline كبيرة & 0.84 & 4.17 & يعتقد بأن الطالب هو محور العملية التعليمية التعلمية . & 40 & 6 \\
\hline كبيرة & 0.92 & 4.15 & يدرك أهمية دوره في عصر العولمة والانفتاح. & 41 & 8 \\
\hline كبيرة & 0.93 & 4.14 & يؤمن بأن هدف التعليم هو تنمية مهارات التعلم . & 44 & 9 \\
\hline كبيرة & 0.92 & 4.07 & يؤمن بأنه ليس المصدر الوحيد للمعرفة . & 38 & 10 \\
\hline 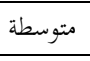 & 1.18 & 3.21 & يعتقد أن إمكانيته مهددة من قبل التقنيات التعليمية. & 37 & 11 \\
\hline كبيرة & 0.86 & 4.12 & & \multicolumn{2}{|c|}{ المجال الكلي } \\
\hline
\end{tabular}

\section{نلاحظ من الجدول رقم (4) :}

كان متوسط درجة الموافقة على قيم المعلم (4.12) وتقابل درجة موافقة كبيرة.

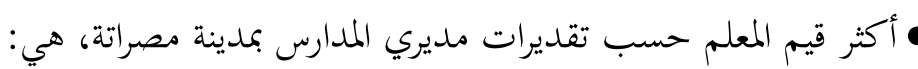
الفقرة (45)"يدرك أهمية المهنة التي يمارسها وقدسيه رسالتها" بمتوسط حسابي (4.55)، وتقابل درجة موافقة كبيرة جدا. ثم الفقرة (42) يعتقد بضرورة تدربه على الجحيد في التقنيات التعليمية بمتوسط حسابي (4.24)، وتقابل درجة موافقة كبيرة جداً.

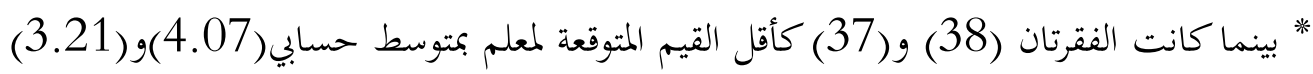
على الترتيب. 
1. أن درجة موافقة المديرين لأدوار المعلم كانت كبيرة (4.10)، وهذا يعني أن هنالك اتفاقاً كبيراً بينهم حول أدوار المعلم في استخدام التقنيات ، وقد يعود سبب ذلك إلى: شعور المديرين بأهمية التقنيات التعليمية في العملية التعليمية.

بلده مشاريع التطوير التربوي في ليبيا التي تمدف إلى إدماج التقنيات التعليمية في التعليم. 2. وجاءت الفقرة (8) "يوظف التقنيات التعليمية في حل المشكلات التعليمية" بـأعلى لئي متوسط حسابي بلغ (4.28) وتقابل درجة موافقة كبيرة جداً. وهذا يعني أن هناك اتفاقاً كبيراً بينهم حول أدوار المعلم وقد يعود سبب ذلك إلى:

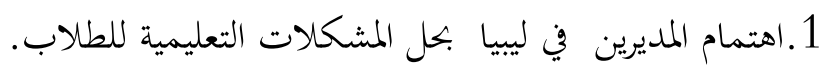
2. مواكبة النظام التربوي في ليبيا لاستخدام للتقنيات التعليمية كما هو الحال في باقي دول العالم، وجاءت الفقرة (4)" يساعد الطلاب في الوصول على المعلومات" بالمرتبة الثانية ومتوسط حسابي (4.25) وتقابل درجة موافقة كبيراً جداً، وهذا يعني أن هنالك اتفاقاً كبيراً بينهم حول بوليه أدوار المعلم ، وقد يعود ذلك إلى:

أ- أهمية التطور وسرعة الوصول إلى المعلومات عن طريق التقنيات الحمديثة. ب-نظراً لأهمية وصول المعلومات إلى ذهن الطلاب بشكل أسهل وبشكل مباشر والاستفادة منها - أكثر 3 ـ وجاءت في الفقرة (6) في المرتبة الأخيرة لمذا المجال "يحاور ويناقش باستخدام التقنيات التربوية"، وقد يعود ذلك إلى 1. تكنولوجيا المعلومات والاتصالات أصبحت لغة العصر والاتصال مع العالم. 2. لسهولة الاتصال في معالجة الصعوبات التي تواجهـم في إنشاء أي مشروع. وتتوافق هذه النتائج مع نتائج دراسة (عبابنة، وشعيب، 2009). 


\section{مناقشة الجمال الثاني معارف المعلم :}

أن درجة موافقة مديرين المدارس لمعارف المعلم كانت كبيرة (3.89)، وهذا يعني أن هناك اتفاقاً

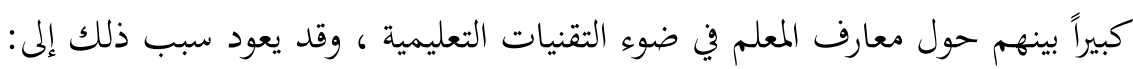
1. أهمية المعارف في التفاعل مع التلاميذ .

2. أهميـة دور التقنيـات التعليميـة في تـوفير استحضــار المعلومـات والمعـارف في الفصـول المدرسية. 1. جاءت الفقرة (21) "يواكب علوم العصر وتقنياته المتطورة" بأعلى متوسط حسابي بلغ

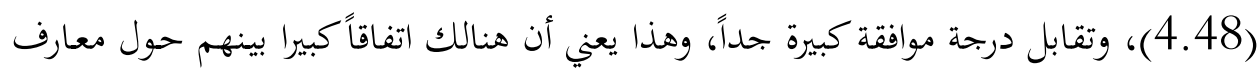
المعلم وفد يعود سبب ذلك إلى: 1. أهمية استخدام التقنيات المتطورة في عصر الانفجار المعريف. 2. أهمية استخدام التقنيات في ليبيا بتطوير المعارف الواردة في المناهج. 3. تغيير وتطوير الواقع بما يناسب تراكم المعارف في العالم الخارجي.

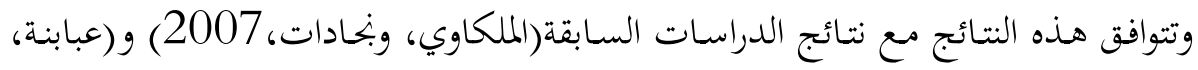
وشعيب، ونتو 2009).

\section{مناقشة الجمال الثالث مهارات المعلم :}

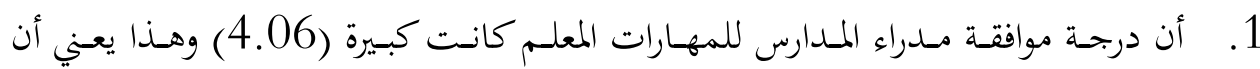
هنالك اتفاقاً كبيرا بينهم حول مهارات المعلم في استخدام التقنيات التعليمية ، وقد يعود سبب ذلك إلى: شعور بعض مدراء المدارس بأهمية امتلاك المعلم لمهارات اللازمة في استخدام التقنيات التعليمية. أهمية التطور الحديث في ليبيا بإدماج التقنيات في عمليات التدريس والإدارة المدرسية.

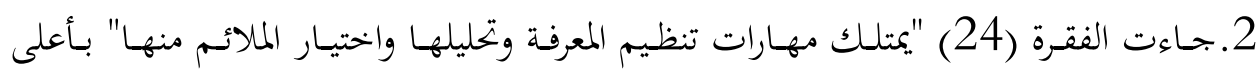
متوسط حسابي بلغ (4.30) وتقابل درجة موافقة كبيرة جداً ، وهذا يعني أن هنالك اتفاقاً كبيراً بينهم حول مهارات المعلم ، وقد يعود ذلك إلى : 
3. جـاءت الفقـرة (32) "يمتلـك المقــدرة على الـدخول على قواعـد البيانـات" بمتوسط حســابي (4.21) وتقابل درجة موافقة كبيرة جداً ، وقد يعود ذلك إلى أهمية قدرة المعلم على استخدام هذه التكنولوجيا في الوصول إلى قواعد البيانات واختبار المعرفة المناسبة للطلاب .

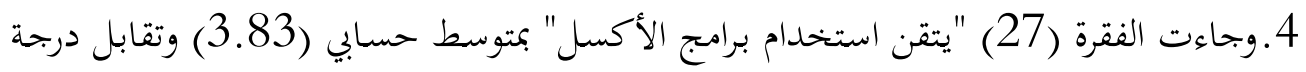

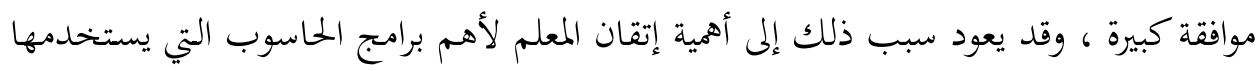

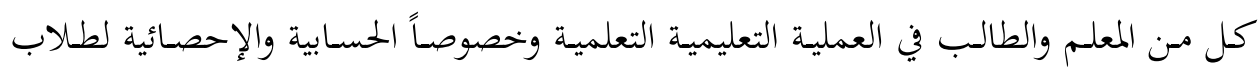
الثانوية العلمية. 5. وجاءت الفقرة (28) "يتقن استخدام برنامج الرسام" بمتوسط حسابي (3.76) وتقابل درجة

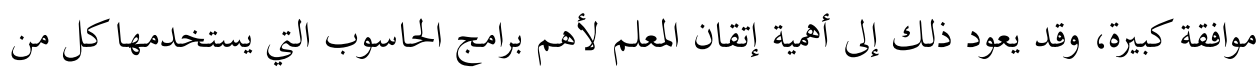

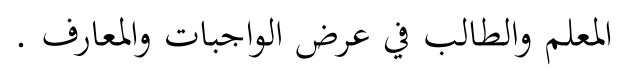
وتتوافق هذه النتائج مع نتائج الدراسات السابقة (الملكاوي، وبنحادات، ولمعات 2007) و وعبابنة، وشعيب، 2009) في تركيزها على أهمية امتلاك المعلم لمهارات استخدام الحاسوب وبرابحه.

\section{مناقشة الجمال الرابع قيم المعلم :}

1. أن درجه موافقة مدراء المدارس لقيم المعلم كانت كبيرة (4.12)، وهذا يعني أن هنالك اتفاقاً كبيرة بينهم حول قيم المعلم في ضوء تكنولوجيا المعلومات والاتصالات، وقد يعود سبب موراء ذلك إلى:

ه أدراك مديرو المدارس أن قيم البحتمع الليبي تؤثر في عملية التعليم والتعلم.

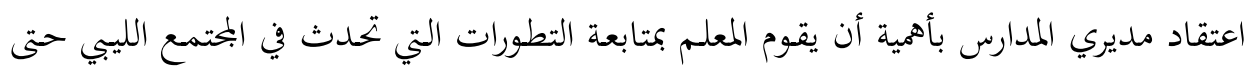
يكون تعليمه للطلاب موافقا للمجتمع الذي يعيشون فيه ، والقيم المرتبطة باستخدام التقنيات التعليمية. 2. وجـاءت الفقرة (45) "يـدرك أهميـة المهنة التي يمارسها وقدسية رسـالتها" بـأعلى متوسط حسابي بلغ (4.55) وتقابل درجة موافقة كبيرة جداً، وهذا يعني أن هنالك اتفاقاً كبير بينهم حول قيم المعلم ، وقد يعود ذلك إلى: 
هركيز مدراء المدارس على أهمية مهنة التعليم شعور المعلم بالإخلاص للمهنة التي يمارسوها.

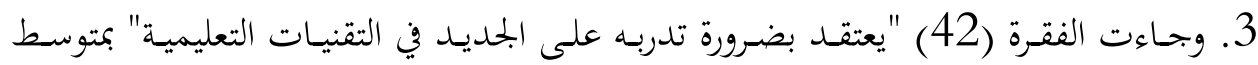

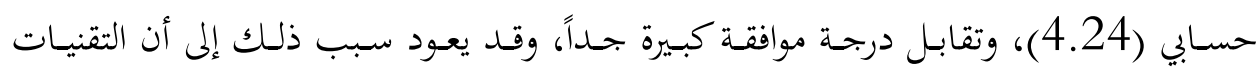
التعليمية تشهد تغيرات كبيرة ومستمرة تستلزم من المعلم التنمية المهنية المتواصلة.

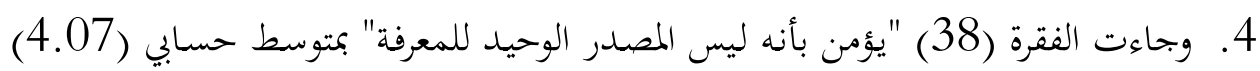
وتقابل درجة موافقة كبيرة، وجاءت الفقرة (37) "يعتقد أن مكانته مهددة من قبل التقنيات التعليمية" بمتوسط حسابي (3.21)، وتقابل درجة موافقة متوسطة، وقد يعود ذلك إلى اعتقاد مديري المدارس بأن دور المعلم سيزداد، وليس معرضا للتهديد بالاستبدال بالتقنيات .

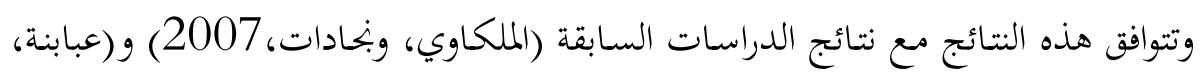

$$
\text { وشعيب، 2009). }
$$

\section{في ضوء نتائج الدراسة يوصي الباحث بالآيت :}

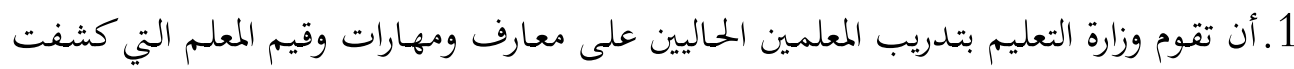

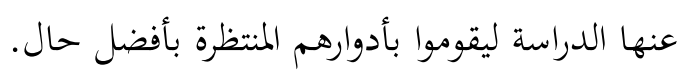

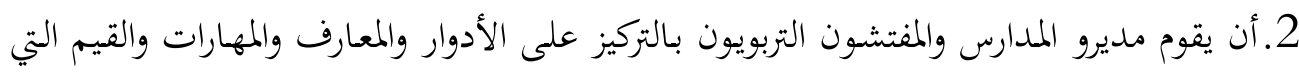
كشفت عنها الدراسة أثناء تعاملهم مع العاملين في المدارس وخصوصا المعلمين.

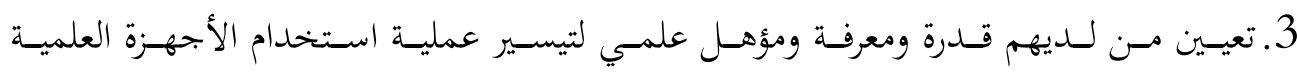
(التكنولوجية) ونشرها في جميع المدارس . 4. العناية بسد النقص في حاجات المعلمين المهنية المتعلقة باستعمال التكنولوجيا.

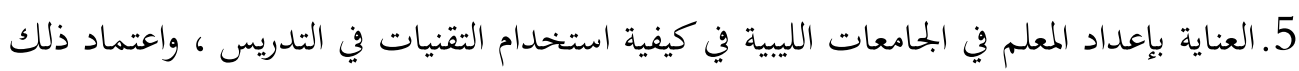
مقرر في الخطة الدراسية للطالب في كليات التربية. 
6. إطلاع المعلمين على المستجدات في عالم التقنيات وتعريفهم بالوسائل والأساليب الفعالة بأبحاه

حل المشكلات التربوية تكنولوجياً.

$$
\text { المقترحات : }
$$

ويوصي الباحث بإجراء الدراسات التالية:

1. إجراء بحثث مماثل في التعليم العالي على (عضو هيئة التدريس) في ضوء تطورات عالم

التكنولوجيا.

2. إجراء بحـث مماثل يتناول أدوار وخصائص المعلم المأمولة مستقبلا في مدن أخرى مـن 


\section{المراجع}

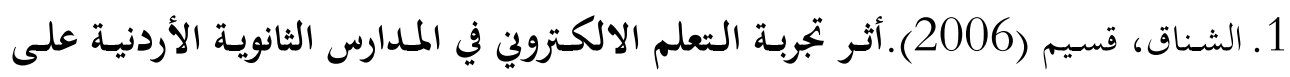

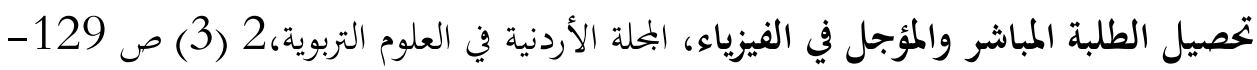

2. الحيلة، محمد محمود(2001). التكنولوجيا التعليمية والمعلوماتية، الطبعة الأولى. 3. محافظة ، محمـد جهاد (2006) ، مدرسـة المسـتقبل - مجموعـة رؤى وأفكـار ودراسـات معاصرة ، دار الكتاب الجامعي ، غزة ، فلسطين. 4. عبـد السـلام، عبـد السـلام مصطفي(2009). تـدريس العلـوم وإعـداد المعلـم - وتكامـل النظرية والممارسة، الطبعة الأولى، جامعة المنصورة . 5. عبابنة، صالح أحمد، وشعيب، محمد رمضان (2009). النظام التربوي في ضوء تكنولوجيا المعلومات والإتصالات : منظور مستقبلي، ورقة عمل مقدمة إلى المؤتمر العلمي الأول للعلوم الإنسانية، جامعة السابع من أبريل (21-2009/4/23).

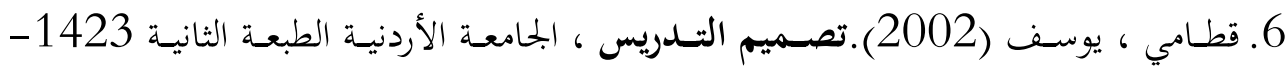
2002 الخطيب، قاسم (2005).حوسبة المناهج، رسالة المعلم، 43 (3-4)، عمان، الأردن. 7. ملكاوي، ناظم محمود، و بنحادات، عبد السلام(2007). تحديات التربية العربية في القرن الحادي والعشرين وأثرها في تحديد دور معلم المستقبل. بحلة جامعة الشـارقة للعلوم الشرعية والإنسانية 4 (2)، 143-159. 